\title{
On Becoming a Person: Perspectives from Carl Rogers, Huineng, Wang Yangming, and Ken Wilber
}

\author{
Caifang $\mathrm{ZHU}$ \\ Director, Beijing Counseling and Meditation Center, Beijing, China \\ caifangzhu@hotmail.com \\ Hongyu LIU \\ Senior Administrator, Faculty of Psychology, Beijing Normal University, \\ Beijing, China \\ liuhongyu@bnu.edu.cn
}

\begin{abstract}
On Becoming a Person: A Therapist's View of Psychotherapy published in 1961 is believed to be the most well-known book written by Carl Rogers, the quintessential humanistic psychologist and psychotherapist. Chapter 6 seems to represent the core of this book: What It Means to Become a Person? To this seminal question, Rogers gives a fourfold answer: A person who has become himself demonstrates the following qualities: openness to experience, trust in one's own organism, an internal locus of evaluation, and willingness to be a process. Much of Rogers' conception of a person who has emerged from therapy and become himself sounds familiar to Chinese readers who know Huineng, the real founder of Chan Buddhism in the eighth century China and Wang Yangming, a neo-Confucian philosopher in the $15^{\text {th }}$ and 16 th century China. This paper will try to present a brief comparative study of the concept and performance of a highly functional person who has become himself from the standpoint of Rogers, Huineng, Wang and Wilber. We will focus the discussion on two fundamental questions: What does it mean to become oneself (Who am I)? How do we actualize ourselves?

After counseling tens of thousands of clients over a couple of decades, Carl Rogers (1902-1987) summarized as a psychotherapist that the various problems of his clients boil down to one search, "Who am I, really? How can I get in touch with this real self, underlying all my surface behavior? How can I become myself?" (Rogers, 2020, p. 108). From this Rogers extrapolates that the purpose of education, like counseling and psychotherapy, is to provide facility to allow students to become themselves. Like the client-centered therapy, which later is renamed as person-centered therapy
\end{abstract}


(Rogers, 1980), the method in education is the student-centered approach (Rogers, 1951, 1961/2020). In the following I will elucidate the views and practices of Rogers, Huineng and Wang around the two questions: Who am I? How could I become myself?

\section{Keywords}

self - Carl Rogers - Huineng - Wang Yangming - Ken Wilber

\section{Rogers on Self as Fluid Living Organism}

In On Becoming a Person, Rogers (1961/2020) gives extensive definitions and elaborations on the self or what he calls the person that has emerged after a complete and effective therapy based on the client-centered approach. In this paper I use the terms of self and person interchangeably in the Rogerian context. The Rogerian self is also expressed as authentic self, realized self, emerged self or fully functioning self. Rogers (1951) attempted to theorize the formation of the structure of the self in the last chapter of The Client Centered Therapy. "As a result of interaction with the environment, and particularly as a result of evaluational interaction with others, the structure of self is formed - an organized, fluid, but consistent conceptual pattern of perceptions of characteristics and relationships of the "I" or the "me," together with values attached to these concepts" (Rogers, 1951, p. 498). If that attempt seems to go along the main stream of Western psychology in structuring or reifying the self, such as the cohesive self (Kohut, 1977) constructed in his self psychology, then we find that Rogers (1961/2020) is more inclined to define the self as an ongoing process of experiencing without solid or core structures. Even the word "consistent" that he used in 1951 seems to be missing from the self that bears the following basic characteristics (Rogers, 202O):

1. Openness to experience. The increasing ability to be open to one's experience makes a person far more realistic in dealing with new people, new situations and new problems. Such a person can face conflicting evidence without hiding or forcing closure upon the situation.

2. Trust in one's own organism. The person increasingly discovers that his own living organism is trustworthy, that it is a suitable instrument for discovering the most satisfying behavior in each immediate situation.

3. An Internal locus of evaluation. Rogers believes a person emerging from therapy has learned to evaluate himself and the world from his own experience rather than that of outsiders 
4. Willingness to be a process. An emerged person accepts "a more satisfying realization that he is not a fixed entity, but a process of becoming". Another way Rogers describes such a person is "a stream of becoming, not a finished product... a fluid process, not a fixed and static entity; a flowing river of change, not a block of solid material; a continually changing constellation of potentialities, not a fixed quantity of traits (p. 122).

Above we have tentatively formulated the essential features of the realized person Rogers described. It is noteworthy, however, for (2) Rogers (2020) also acknowledges "his organism would not by any means be infallible" (p. 118, 19o). But because he is open to experiences, he is quick to notice and correct the choices in error. I have a student who tends to trust her own organism very much. She often tells me how she feels the other person in the remote distance or close by. She would give a narrative of what the perceived person was thinking, feeling and behaving. However, she would never check with that person to see whether her perception was mistaken or correct. She thus believes her intuitive perception is infallible. When I had similar intuitive perceptions about my parents, I used to call them up and more often than not they would decline my intuitive perceptions or thoughts about what was happening to them. Interestingly, Rogers might be skeptical about such transpersonal perception of the organism until the last ten years in his life (Kirschenbaum, 2007).

Having delineated what a realized person is like or "who am I?", now let us turn to the second of the seminal question: how can I become myself, become a realized person through therapy or education? Among various discourses in his works, Rogers (2020) appears most clear-cut and to-the-point in chapter six "What It Means to Become a Person" in answer to this question. The process of becoming a realized person, he states, generally entails three steps as follows.

1. Getting Behind the Mask. Many people especially those who are psychologically under-functioning or dysfunctional don't even know that they have been hiding behind the mask too long and too deep. Rogers cited a client who used to be an appeaser, never "being set and definite about things"; she did not know whether she had any convictions to stand up for. "I have not been really honestly being myself, or actually knowing what my real self is, and I have been playing a sort of false role" (Rogers, 2020, p.109).

So, there is no way for these people to take the initiative in working on removing their mask. It is the therapist or educator's job to empathize them first, to think their thoughts and feel their feelings. Only after being empathically listened to and responded to can the client or student possibly be willing to get behind the mask and explore the real thoughts and 
inner emotions. Rogers cited the other client that had gone through her whole therapy. She reports that looking back she had to "peel off layer after layer of defenses...I didn't know what was at the bottom and I was very afraid to find out, but I had to keep on trying" (Rogers, 2020, p.110).

2. The Experiencing of Feeling. When one gets behind his mask to explore his real self in a safe and supportive environment, one enters what Rogers calls "pure culture" where one literally feels various emotions (fear, anger, anxiety, joy, tenderness) that come by and go away moment by moment. A case excerpt Rogers cited in his counseling experience is a graduate student who was bothered by a frightened feeling of failing to get his $\mathrm{PhD}$ degree. He went through an emotional experience of "a pleading little boy, supplicating, begging and dependent". Later he was amazed he had been so genuinely praying not to fail. An individual in such a moment, Rogers (2020) said, "is coming to be what he is. When a person has, throughout therapy, experienced in this fashion all the emotions which organismiscally arise in him, and has experienced them in this knowing and open manner, then he has experienced himself, in all the richness that exists within himself. He has become what he is (p.113)".

3. The Discovery of Self in Experience. The client Rogers (2O2O) cited in this case scenario was trying to figure out her pattern. But she found there were too many pieces in her pattern to see where they each would fit. Feeling tired of trying to figure out, she "discovered that left to themselves the jumbled pieces fall quite naturally into their own places, and a living pattern emerges without any effort at all on your own. Your job is just to discover it (p.114)". Rogers summarizes the discovery of self this way, "the real self is something which is comfortably discovered in one's experiences, not something imposed on it". This something as the real self, Roger said, is "a living, breathing, feeling, fluctuating process-in short, he becomes a person" (p. 114).

Applying such discovery of the self in education as demonstrated in chapters 13, 14 and 15, Rogers vehemently encourages the student-centered approach, urging students to read, think, explore and exchange on their own rather than relying on the instructor. The instructor is more of a facilitator than an authority to feed or cram students with his own experience or knowledge. Much of what I did as a college instructor of English in the late 1980s and 199os in Beijing was based on the pedagogy of student-centered communicative approach. I encouraged students to pair up or form small groups to perform a short situational play or act out a story of the text in study. I had not known until many years later that the student-centered communicative approach in English as a Second/ 
Foreign Language (ESL) learning and teaching is modelled on Rogers theory and practice.

Having portrayed the Rogerian self and the way to become the self through therapy or education, we shall now move on to take a look at what Huineng would say about the two seminal questions.

\section{$2 \quad$ Huineng on Self as Non-Attachment}

Huineng is regarded as the real founder of Chan Buddhism, which is believed to be an integration of vernacular Daoism and Indian Buddhism that was introduced to China around the first century A.D. (Ma, 2007; Yinshun, 2010). One of the distinctive features of Chan Buddhism (better known as Chan in Chinese or Zen in Japanese) is that it emphasizes the immediacy of the functioning fluid mind rather than the transcendence of consciousness or spirituality (Shengyen \& Stevenson, 2001; Zhu, 2012, 2020).

When I say in the introduction that Roger's notion of self may sound familiar to many Chinese readers who know Huineng, I am particularly referring to the Rogerian self as "a stream of becoming", "a fluid process" (Rogers, 2020, p. 122). In Chapter Four "Meditation and Wisdom", Huineng (1996) says, "Learned audience, it has been the tradition of our school to take idea-lessness as our object, formlessness as the substance and non-attachment as the fundamental principle (wú zhù wéi běn无住为本)... Non-attachment is the characteristic of the nature of our human mind." (p. 83). Non-attachment of the mind can be understood as just another expression of flowing or fluidity and this fluid process or stream is regarded as the fundamental nature of our human mind. Such a mind or rather such a state of mind is fluid and self aware at the same time.

Although such a state of mind is innate but often people are no longer able to experience it as their mind may have been congested or stagnated due to various conditioning in the process of socialization and adaptation. Intentional meditation practice may provide them a chance to refresh or reactivate the original mind that continually flows with open awareness. This is an equivalent to the saying in the Diamond Sutra that an awakened person activates his attentive mind without being attached to anything. We are delighted to notice that meditation is part of the Integral Drama Base Pedagogy (IDBD) that Ma Li-wen and Subbiondo (2021) have been advocating in her teaching at the faculty of education, Beijing Normal University.

Let me now mention another standpoint of the realized person in the Rogerian context, be he a therapist, client or just an individual person. It is congruence, the attitude a realized person adopts in his professional or 
daily interaction with others. Basically he is straightforward saying what he means and what he feels inwardly. Again, I find this quality is well elucidated in Huineng's Platform Sutra. "Learned audience, to practice the Samadhi of Oneness is to make it a rule to be straightforward on all occasions, no matter whether we are walking, standing, sitting, or reclining...Don't let your mind be crooked and practice straightforwardness with your lips only. Don't let your mouth say Samadhi of Oneness and not practice straightforwardness in mind. We should practice straightforwardness and not attach ourselves to anything" (Huineng, 1996, p.81).

Rogers visited China twice. The first visit was when he was a junior at University of Wisconsin in 1922 (Rogers, 1961/2020). He was chosen as a representative of his university to attend a world Christian Youth Conference held in Beijing. After the conference he travelled extensively in China for a few months presumably studying and visiting. Shortly after he got back to US, he gave up his Protestant belief his parents had taught him. The second time he visited China was in early 198 os when China reopened to the world. Rogers was then in his eighties and his psychology and philosophy about human nature and education have pretty much settled.

The realized person in Rogerian humanistic psychology sounds similar to the awakened person that Huineng describes in the wisdom tradition of Chan. Given Rogers's personal experience in China that he spoke highly of, I have suspected that Rogers's theory of humanistic psychology especially his concept of self and its resultant philosophy of therapy and education might have been impacted by Chan and Daoism, but Rogers (2020) does not have much explicit expression of such kind (Kirschenbaum, 2007), significantly less than Maslow (1971) expresses in The Farther Reaches of Human Nature. I will keep my hypothesis open before I have a more thorough research on this. Having introduced Huineng, we can now move on to Wang Yangming who apparently engaged himself in the practice of Chan in his early life but shifted to neo-Confucianism later.

\section{3}

\section{Wang Yangming on Self as Intuitive Knowledge}

Zhu Xi (1130-1200) and Wang Yangming (1472-1529) are generally regarded as the greatest philosophers of neo-Confucianism that thrived in the Song and Ming dynasties in China. Roughly they might be compared to Hegel and Kant in German philosophy. Neo-Confucianism has two offshoots, the school of principle (li xue 理学) and the school of mind (xin xue 心学). Zhu is the greatest synthesizer of the school of principle and Wang the school of mind. Among 
many of Wang's influential contributions to the philosophical assumptions and speculations of human mind and education is the theory of oneness between knowledge and behavior (zhixin heyi知行合一) and that of extension of intuitive knowledge (Zhi liangzhi 致良知). Roger's congruence is likened to Wang's zhixin heyi and Roger's actualized person seems to be comparable to the person with the extension of intuitive knowledge in Wang's theory.

CHEN Lai (1991) elucidates the theory of zhixin heyi in four points.

1. Knowing and action are of the same essence. Wang believes that knowing and action are inherently connected to each other. Knowing necessarily leads to corresponding actions. His students asked him why some people refrain from practicing filial piety to their father and brotherhood to his elder brothers although they all know these social norms. Wang replied that these people have been blocked by selfish desires so that knowing and action are no longer inseparable. "There is no knowledge without corresponding action. Knowing without corresponding action is not knowing" (Chen, 1991, p. 271). The following three points further elaborate the inseparable relationship between knowing and action.

2. Real knowledge is the preparation for action. Knowing without action is insufficient as knowledge. Knowing or knowledge in Wang's context means the real or authentic knowledge (zheng zhi真知). Such knowledge has been differentiated by Wang's predecessors from general knowledge.

3. Knowing is the beginning of action and action is the fruition of knowledge (Chen, 1991, p. 273). Wang further elaborates that when one is really thorough, speaking of knowing he understands it already contains the aspect of action; speaking of action, he understands it already contains the aspect of knowledge. From a dynamic perspective of process, each is inclusive of the other.

4. Knowledge is the idea for action and action is practice of the knowledge (Chen, 1991, 274). In other words, action is the means of realizing the knowledge. Action is not a blind horse that takes directions randomly. It needs knowledge to direct its course and steps. They are mutually dependent.

Wang's dialectical relationship of knowing and action seems to predict the contemporary dynamics of cognition, emotion and behavior in rational emotive behavior therapy (REBT) and cognitive behavior therapy (Свт). Cognition impacts emotions and behaviors. Emotions and behaviors result from cognition. Somewhat different from Wang's single direction impact is that each of the other two variables (emotions and behaviors) in REBT (Ellis and Ellis, 2019) and свт can be argued as a source that produces impact on the others 
including cognition. So, the influence is not linear but reciprocal in a triangle diagram.

While the oneness of knowing and action represents the relatively early theory of Wang, extending the intuitive knowledge finalizes the essence of his teaching. Wang's advocacy of the theory of extending the intuitive knowledge in his later life is a result of his interpretation of extension of knowledge (zhi zhi 致知) taught in the Great Learning (Wang, 2016), one of the four books often compared to be the bible of Confucian classics. For Wang, what constitutes the core of Great Learning, namely, the three major cords and eight minor wires, simply boils down to the practice of extending the intuitive knowledge. "What is the intuitive knowledge? It is simply the inner light of our mind, the original unity of the universe, or as the Great Learning calls it, the illustrious virtue" (Fung, 1948, p. 315).

According to Wang (2019), this intuitive knowledge, first mentioned by Mencius, second only to Confucius in the Confucian tradition, appears to be the innermost or fundamental structure of the sage that Wang's teaching aspires to become. Such quality of the sage has in fact always been within each and every person, according to Wang, much like the Buddha nature inherent in everyone, but most probably such intuitive knowledge has been blocked, covered or obscured by various unwholesome thoughts and believes (Du, 1992). So, the practice of extending the intuitive knowledge is simply to recover and reclaim it. According to Wang's Four-Sentence Tenet, the way of recovery is doing the good and removing the evil.

The closest Rogerian concept to the intuitive knowledge is perhaps congruence. Wang's awakening or enlightenment experience was through sitting meditation in a dark cave while he was in exile due to political persecution. After Wang decides to deviate from Chan Buddhism and follow the Confucian path, he replaces meditation practice with the cultivation of sincerity. The emphasis on sincerity in Wang's teaching evolves into the extension of the intuitive knowledge (Fung, 1948).

Now, what is the effective way to teach and realize he extension of intuitive knowledge? In the Four-Sentence Tenet, the third sentence says: recognizing the good and bad is the manifestation of intuitive knowledge. This sounds too general and abstract to be easily applied in educational circumstances until we read a showcase in Wang's Record of Instructions. A burglar was once caught in the house of Wang's disciple. To educate the thief, the captor indeed applied the teaching of extending the intuitive knowledge, but it apparently did not work with the thief who mocked, "Tell me, please, where is my intuitive knowledge?" Since it was hot day, so the captor asked 
the thief to take off his coat, and then the shirt. When the thief was asked to take off his pants as well, he hesitated complaining, "That does not seem to be quite right". At this point, the captor shouted, "There is your intuitive knowledge" (Fung, 1948, p. 313).

To correspond to the call of Ma and Subbiondo (2021), we may use the above story as a script for an integral drama to invite students to act it out. The script may be integrated with Rogerian sense of becoming a person. The process for a group of students to write, design and act out this drama can be a great opportunity for them to experience the extension of intuitive knowledge.

If Rogerian congruence is somewhat comparable to Wang's sincerity and intuitive knowledge, they seem to differ in that Rogers does not talk about differentiation of good and evil while Wang does. What Rogers differentiates is congruence and incongruence, the latter being the attitude of people who are psychologically defensive or malfunctioning. People with the attitude of congruence, on the other hand, are open, authentic and highly or fully functioning. They are self-realized people in Rogerian psychology.

Another point of comparison is that unlike Roger's acknowledgement that trust in organism might be wrong sometimes, Wang does not seem to mention that the intuitive knowledge could be misleading. Rogers was modern, scientific, psychological and disenchanted although he had been religious in his early life and spiritual in his last ten years or so. Wang was ancient, pragmatic and intuitive and spiritual or transpersonal. The quality of the intuitive knowledge Wang describes may be better matched by the Being-values or Metaneeds of the Being-persons Maslow (1971) depicts in Theory Z.

Last but not the least, I have observed that $\mathrm{Du}(1992)$ frequently uses the Rogerian concept of self-realization to describe the sage personality Wang (2019) advocates. "Therefore, although man is endowed with the innate sageliness, he must learn how to become a sage in the daily existence. Such learning requires a continual process of self-realization, a process of realizing the sageliness in each of us" (p. 462). Recognized as a leading neo-Confucianist scholar internationally, Du said decades ago that contemporary neo-Confucianism needs to travel through Tokyo, Boston, New York, London and Paris before resettling down to reconfigure in Beijing. As his student my guess is neo-Confucianism needs to have extensive dialogue with and integrate democracy, capitalism and individualism to come up with contemporary neo-Confucianism that defines the self anew. For this, Ken Wilber's integral psychology might be able to shed some light. 
Although Rogers, Huineng and Wang all make some kind of differentiation of the self, they tend to be overwhelmingly interested in the development of the realized self primarily from a personal, psychological and spiritual perspective. Ken Wilber, a contemporary transpersonal and integral psychologist, however, provides a comprehensive self growth map using the perspective of what he calls "all quadrants and all levels".

Roughly Wilber (2000) classifies the self into the proximate self (closer to the real self) and the distal self (farther away from the real self). When the proximate and distal selves are put together, Wilber calls it the overall self. The proximate self, according to Wilber, is "some sort of observing self (an inner subject or watcher" and the distal self is "some sort of observed self (some objective things that you can see or know about yourself" (p.33). The proximate self and distal self are also called "I" and "me" respectively, which is reminiscent of William James' (189o/1981;1892/1984) portrait of the self.

William James (1842-1910) classifies the self into the empirical Self (also known as the Me, or the Known) and the pure Ego (the I, the Thought, the Thinker or the Knower). The term of the Thought seems to be preferred in the Principles of Psychology first published in 1890 and the term Knower is very seldom used. In its revised shortened version, Psychology: A Briefer Course first published in 1892, however, James (1892/1984) comes up with the pair of the Knower and the Known to occasionally replace the Thought and the Me.

Under the empirical self are the three "constituents" or sub-class selves: the material self, the social self and the spiritual self. The super Ego is by itselfthe Thought. If I summarize each of the Jamesian selves in one sentence, then

- The material self is the me who consists of one's physical body, one's immediate family, belongings and the like;

- The social self is the me recognized by friends, peers and colleagues;

- The spiritual self is the whole collection of the stream of thoughts or consciousness (thoughts and consciousness are interchangeable in James' writings) as the object to BE APPROPRIATED BY THE KNOWER, which is the Thought;

- The Thought is that particular impulse, instant or state of the stream of thoughts that is the PRESENTLY PRESIDING (e.g. judging and appropriating) over all the bygones of the stream and IDENTIFY WITH THEM ALL BY ADOPTING the thought before it which has adopted the one that had gone before itself and so forth in an unbroken succession (Zhu, unpublished paper). 
We see from the above that James' Thought or I can observe the physical self, the social self and the spiritual self. Similarly, Wilber says that the proximate self can go through a series of fulcrum or a milestone of its own development. "Within limits, the self can temporarily roam all over the spectrum of consciousness-it can regress, or move down the holarchy of being and knowing; it can spiral, reconsolidate, and return." (Wilber, 2000, p.35). Ideally an individual's spectrum of consciousness develops as follows in the diagram:

\section{Fulcrum- o birth}

\begin{tabular}{lll}
\hline F-1 & $\begin{array}{l}\text { physical self } \\
\text { emotional self }\end{array}$ & $\begin{array}{l}\text { autistic, symbolic, self-only } \\
\text { impulsive, magical, narcissistic, } \\
\text { hedonic }\end{array}$ \\
F-3 & self- concept & $\begin{array}{l}\text { safety-power } \\
\text { mythic-membership } \\
\text { F-4 }\end{array}$ \\
role self & mature ego & conformist, rational-reflexive \\
F-5 & centaur & universal, global \\
F-6 & psychic & panenhenic, yogic \\
F-7 & subtle & saintly \\
F-8 & causal/nondual & sage \\
F-9 & &
\end{tabular}

Empirical evidence has consistently demonstrated, Wilber (2000) points out, that the proximate self's center of gravity "tends to hover around one basic level of consciousness at any given time. This means, for example, that if you give individuals a test of ego development, about 50 percent of their answers will come from one level, and about 25 percent from the level immediately above or below it" (p. 35-36).

This 10-Fulcrum stages of consciousness development is referred to as the All Levels in Wilber's integral paradigm of All Levels and All Quadrants. All quadrants refers to the four quadrants of

(1) the upper left quadrant of "I" featuring individual mind and body;

(2) the lower left quadrant of "We" featuring collective culture of the self;

(3) the upper right quadrant of "It" representing the science (biology, neuropsychology, chemistry) of the self;

(4) the lower right quadrant of "Its" representing the society and environment that contributes to the shaping of the ecological self. 
Generally speaking, while the Rogerian self finds (1) a comfort zone, the Confucian model of Wang's self finds (2) more congenial. To develop an integral self means to be aware of all the four quadrants and ten levels of consciousness. Problems that occur at certain level of consciousness or specific quadrant need to find corresponding therapies or practices. Exactly how to practice integral psychology? For this, Wilber (2008) writes a specific book called Integral Life Practice: A 21st-Century Blueprint for Physical Health, Emotional Balance, Mental Clarity, and Spiritual Awakening. Wilber would claim integral life practice based on integral psychology is applicable to all people. Each one is likely to find what he needs regardless of one's gender, age, race, religion and education etc. Due to limited space of this paper, I will stop short of further explanations of the practice.

\section{$5 \quad$ Epilogue}

What does it mean to fully become a person himself? How does he realize or actualize his authentic self? These are fundamental or perennial questions for psychologists, educators, philosophers to address. In this article we have assembled the answers from two modern Americans and two medieval Chinese. Speaking mostly as a psychotherapist, Rogers claims the client who emerges from therapy realizes that his authentic self is a fluid stream of felt feelings and thoughts and that to become such a person requires opening to new experiences and maintaining congruence inside and outside. Huineng as a Chan Buddhism leader in medieval China seems to say: Hey, Dr. Rogers, I am delighted your notion of the self sounds so familiar to us. We have been actualizing the fluid self of no-attachment since the gth century in China. Would you like to visit China again? I can share with my experiences of mindfulness meditation practice that enables us to be intimate with the fluid self and you may share with my lay practitioners how to develop an interpersonal intimate relationship. Hearing Huineng out, Wang Yangming says, absorbing the essence you teach and retaining the Confucian tradition, I now teach extending the intuitive knowledge to realize the authentic self, the sageliness in us. And To actualize that, one simply needs to practice sincerity, Wang adds. Wilber smiles noddingly, "great thoughts and great practices, folks. May I put your remarkable achievements of teaching and practice in my All Quadrants All Levels framework? You may decide where you are on the integrative map". 


\section{References}

Chen, L. 陈来 (1991). Song Ming Lixue (Neo-Confucianism in Song and Ming Dynasties). Shengyang, China: Liaoning Education Press.

Du, W-M. 杜维明 (1992). Rujia Chuantong de Xiandai Zhuanhua (The Modernization of Confucian Tradition: Selected works of Du Weiming). Beijing: Zhongguo Guangbo Dianshi Press.

Ellis, A. \& Ellis, D. J. (2019). Rational Emotive Behavior Therapy. Second edition. Washington D.C.: American Psychological Association.

Fung, Y-L. 冯友兰 (1948). A Short History of Chinese Philosophy. New York: Macmillan. James, W. (189o/1981). The Principles of Psychology. Cambridge, Massachusetts: Harvard University Press.

James, W. (1892/1984). Psychology: A Briefer Course. Cambridge, Massachusetts: Harvard University Press. In G Myers (Ed., 1992), William James Writings 1878-1899. New York: Library Classics of the United States, Inc.

Huineng. 慧能(1996). The Sutra of Huineng. Bilingual. (Trans.) HUANG Maolin (Wong Mou-lam), revised by Christmas Humphreys. Changsha, China: Hunan Press.

Ma, T-X. 麻天祥 (2007). Zhongguo Chanzong Sixiang Fazhan Shi (The Developmental History of Chan Buddhism in China, revised edition). Wuhan, China: Wuhan University Press.

Ma, L-W马利文 \& Subbinodo, J. (2021). Integral drama based pedagogy as a practice of integral education: Facilitating the journey of personal transformation. Beijing International Review of Education.

Maslow, A. H. (1971). The farther reaches of human nature. New York: Viking Press.

Kirschenbaum, H. (2007). The Life and Work of Carl Rogers. PCCs Books, UK.

Kohut, H. (1977). The restoration of the self. Chicago: University of Chicago Press.

Rogers, R.C. (1951). Client-centered therapy: Its current practice, implications and theory. Boston: Houghton Mifflin.

Rogers, R. C. (1961/2020). On becoming a person: A therapist's view of psychotherapy. UK: Robinson.

Rogers, R.C. (1980). A way of being. Boston: Houghton Mifflin.

Sheng-yen 圣严, with Stevenson, D. (2001). Hoofprint of the ox. Oxford: Oxford University Press.

Wang, Y-M 王阳明.(2019). The Complete Works of Wang Yangming. Shanghai Guji Press.

Wang, G-X. (2016) (annotated). Great Learning and Doctrine of the Means. Beijing: Zhonghua Shuju.

Wilber, K. (2000). Integral Psychology: Consciousness, spirit, psychology, therapy. Boston: Shambhala.

Wilber, K. (2008). Integral Life Practice: A 21st-Century Blueprint for Physical Health, Emotional Balance, Mental Clarity, and Spiritual Awakening. 
Yinshun 印顺, (2010). Zhongguo Chanzong Shi (The History of Chan Buddhism in China). Beijing: Zhonghua Shuju.

Zhu, C-F 朱彩方. (2020). Chan Buddhism and Meditation. In M. Farias, D. Brazier \& M. Lalljee (Eds.), Oxford Handbook of Meditation. Oxford University Press. Published online. Website.

Zhu, C-F朱彩方. (2020). Grounding and Communication as an Integrative Therapy. In C. Fracasso, S. Krippner, \& H. Friedman (Eds.), Holistic Treatment in Mental Health: A Handbook of Practitioners' Perspectives. Pp.259-272. Jefferson, NC: McFarland Publishing Company, Inc.

Zhu, C-F朱彩方. The Jamesian and Buddhist Models of the Self. Unpublished paper. 
